\title{
Copulatory Urgency: An Evolutionary Perspective of Women's Sexual Desire
}

Accepted Chapter for the Cambridge Handbook of Evolutionary Perspectives on Sexual Psychology

Courtney L. Crosby*

The University of Texas at Austin

${ }^{*}$ Comments and correspondence should be addressed to Courtney L. Crosby

(clcrosby@utexas.edu) The University of Texas at Austin, Department of Psychology, 108 E.

Dean Keeton St., Austin, TX 78712.

Declarations of interest: none

Word count: 9,913 words including the abstract, keywords, references, figures, and tables Acknowledgements: I would like to thank David Buss and Cindy Meston for helpful feedback on this chapter. 


\begin{abstract}
Despite the extensive empirical exploration of sexual desire, only one field explains the proper biological function of this phenomenon - evolutionary psychology. This chapter reviews women's copulatory urgency-individual differences in the experience or intensity of sexual desire-from an evolutionary psychological perspective. An evolutionary psychological perspective of the function of sexual desire can shed light on how deficits in this motivational force may emerge, which may be useful for clinicians when helping patients understand the etiology of sexual desire concerns. An evolutionary psychological perspective of sexual desire further reveals: (1) why men and women differ in their experiences of sexual desire, (2) how natural selection produces individual differences in sexual desire, and (3) how extremes in sexual desire may be associated with hypersexuality, paraphilias, or an evolutionary mismatch between the adaptive problems faced during our species' past and the challenges we face today. I begin the chapter by presenting a brief history of research on sexual desire and highlighting the limitations of early models of sexual responding. Next, I discuss the difficulties of measuring sexual desire, and explain how evolutionary meta-theory can be fruitful when examining context-dependent individual differences in sexual desire. I then describe the impact of several important contextual factors (e.g., age, relationship length, parental effort, partner habituation) on variation in women's sexual desire responses and highlight avenues for future research. The chapter ends by discussing the qualities of compulsive sexual behavior and proposing that extreme variations in sexual desire as we currently understand them may be the result of an evolutionary mismatch. In sum, I suggest that scientists distinguish between sexual desire and sexual arousal, consider evolutionary meta-theory when thinking about context-dependent variation in sexual desire, and be cognizant of potential confounds when examining women's sexual desire responses.
\end{abstract}

Keywords: sexual interest; sexual desire; sexual motivation; sexual urges; libido; sexual behavior; women's hypersexuality; women's sexuality 


\section{"Sex is a part of nature. I go along with nature." - Marilyn Monroe}

Sexual activity is an indispensable part of human nature, as sex icon and American actress Marilyn Monroe pointed out. Engaging in sexual intercourse has historically been requisite for reaching reproductive success in sexually reproducing species. Reproductive success refers to the ability of an individual to produce more viable offspring than conspecific competitors (Darwin, 1859). Women, on average, increase their reproductive success by securing a partner who will invest in her and her future offspring. Women's reproductive success stands in stark contrast to men's, who may experience incremental gains with every sexual encounter they have with a fertile female. Asymmetries in reproductive success, coupled with differences in the minimum obligatory costs of parental investment (Trivers, 1972) render the costs of injudicious sexual decisions greater for women than for men. Additionally, the greater reproductive variance of men has resulted in a more intense sexual selection for men, with the benefits associated with gaining additional sex partners outweighing the potential costs of having sex under some circumstances (Daly, 2001). All else equal, it has historically been more costly for men than for women to forgo sexual opportunities. This cost asymmetry has led to sex differences in our underlying sexual psychology, such as the male sexual over-perception bias (Haselton \& Buss, 2000; Bendixen, 2014), women's higher levels of sexual disgust (Al-Shawaf et al., 2018; Crosby et al., 2020; Tybur et al., 2009), and most relevant for the current chapter: the unique design of women's sexual desire' ${ }^{1}$

\section{What is sexual desire?}

\footnotetext{
${ }^{1}$ Parts of this chapter are adapted with permission from Crosby et al. (2021) and Crosby et al. (2019)
} 
Sexual desire - also referred to as sexual interest, sex drive, or libido - is hypothesized to motivate individuals to engage in sexual activity (Levine, 2003; Meston \& Stanton, 2017). Sexual desire plays an important motivational role in our sexuality, as engaging in sexual activity is associated with various proximate benefits and costs. Potential benefits include pleasure, stress reduction, goal attainment, and emotional commitment (see Meston \& Buss, 2007, for an extensive list of reasons why people have sex). Potential costs include the transmission of sexually transmitted infections (STIs; Al-Shawaf et al., 2018; American Sexual Health Association, 2016; Baggaley et al., 2010; Boily et al., 2009; Centers for Disease Control and Prevention, 2008; National Center for HIV/AIDS, Viral Hepatitis, STD, and TB Prevention, 2011; Seth et al., 2012; Thrall et al., 2000; Varghese et al., 2002), unwanted pregnancies, reputational damage (Gallup et al., 2009), unrequited interest in a romantic relationship, negative emotions such as anger or regret, and sexual opportunity costs (Bersamin et al., 2014; Eshbaugh \& Gute, 2008; Kennair et al., 2016; Owen et al., 2010; Sonnenberg et el., 2013; Tybur et al., 2009). Despite these potential costs, women consistently cite sexual desire as one of the most important among 237 reasons for having sex (Meston \& Buss, 2007). Understanding variation in the desire to engage in sex in light of the potential costs is critical for developing a comprehensive theory of human sexual behavior.

\section{A brief history of sexual desire}

Many scientists and fields of study purport to operationalize and examine sexual desire, and contention exists on how best to define this construct. For example, Freud (2017/1905) described the motivation or interest to engage in sex as a biological, innate, internal drive that propels individuals toward release. Freud's operationalization stands in contrast to other scientists who instead conceptualize sexual desire as an interplay between psychological, 
biological, and social contextual factors that influence individuals regardless of release (Basson, 2002; Toates, 2014). This interplay is evident when reading the clinical literature; sexual desire is described in the clinical literature as thoughts, fantasies, or urges to engage in solo (e.g., masturbation) or dyadic (e.g., sexual intercourse) sexual activity (Basson, 2002; Kaplan, 1977). Sexual desire was left out in initial conceptualizations of the human sexual response. Masters and Johnson's (1966) pioneering work described the human sexual response in four phases, which were hypothesized to operate linearly: excitement, plateau, orgasm, and resolution. According to this model, excitement referred to the physiological arousal response rather than the mental experience of sexual desire (see Rowland \& Gutierrez, 2017, for a review). While Masters and Johnson acknowledged that this model may not be representative of all individuals, they argued that the linear model was useful for understanding the average sexual response. Their model became the gold standard for understanding sexual dysfunctions, being included in both the Diagnostic and Statistical Manual of Mental Disorders (DSM) III (1980) and the DSM-III-R (1987). However, clinicians began to realize the limitations of the Masters and Johnson model when patients presented with sexual concerns that were not encapsulated by their model; mostly, these concerns surrounded a lack of motivation to engage in sex (Leiblum, 2000). In response, Kaplan (1977) added to the Masters and Johnson model, describing the human sexual response as a triphasic model consisting of desire, arousal, and orgasm. While the Kaplan model was a step in the right direction, it, too, was not effective for describing the sexual experiences of most women. Although these linear models of sexual response capture many men's sexual responses, a majority of women do not experience spontaneous sexual desire (Rowland \& Gutierrez, 2017). Rather, receptiveness to sexual stimuli or sexual arousal is critical in women's' experience of sexual desire. 
To incorporate the process of sexual receptivity, Basson (2000) developed the circular model of women's sexual response. In this model, sexual desire is the second stage, following that of sexual arousal ${ }^{2}$. According to this model, women are often in a sexually neutral state. When exposed to cues relevant to sex (e.g., kissing; petting), women may become sexually aroused, which might then lead to the experience of sexual desire (see Figure 1 below, taken from Basson, 2002). Basson's model does not require an orgasmic release to engage in sex; rather, Basson emphasizes the psychological, relational, and contextual components involved in sexual activity. In fact, the primary output of Basson's model is emotional intimacy, which can consist of a combination of psychological or physical intimacy. Basson's model describes the sexual response process for women as a feedback loop, allowing each stage to feed into another stage. That is, these stages need not take place in an ordinal fashion. In sum, Basson's circular sexual response cycle differs from the traditional sexual response cycles that were initially proposed by accounting for a potential lack of spontaneous desire, and better illustrating the sexual responses of most women.

Figure 1. Basson's circular model of women's sexual response

\footnotetext{
${ }^{2}$ Some researchers argue that sexual desire is not distinct from sexual arousal (e.g., Brotto, 2010). I believe that sexual desire and sexual arousal are separate motivational forces. I discuss sexual desire and hypoactive desire disorder (HSDD) as they were described in the DSM-IV-TR.
} 


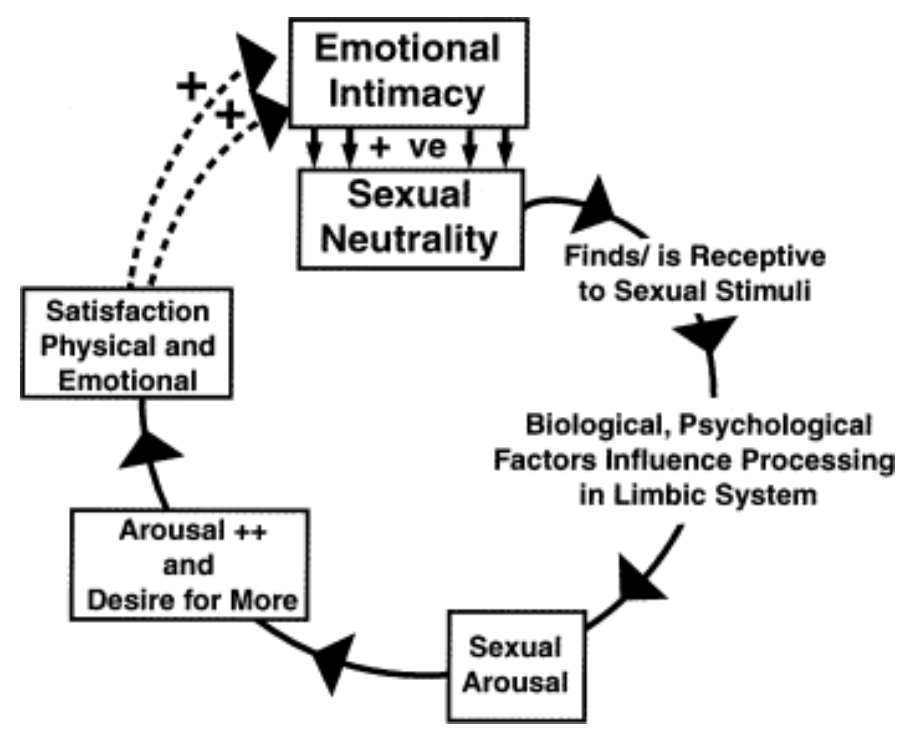

Note. From "Rethinking low sexual desire in women," by R. Basson, 2002, BJOG: An

International Journal of Obstetrics \& Gynaecology, 109(4), p. 357-363.

\section{Sex differences in sexual desire}

In addition to sex differences in sexual response cycles, sexual desire is different between men and women. For example, there are large and robust sex differences in the degree to which people fantasize about sex (Elis \& Symons, 1990; Fisher et al., 2012; Vance et al., 2020). These differences persist across the lifespan and across romantic relationships. A study conducted by Buss and Schmitt in 1993, and has since been replicated (e.g., Buss \& Schmitt, 2019; Schmitt, 2003; Vance et al., 2020), further illuminates sex differences in sexual desire; however, this study focused on the desire for sexual variety. The desire for sexual variety refers to the number of sexual partners an individual wishes to have at a given time point. In this study, participants were asked to report the number of sexual partners they desired over multiple time points (e.g., a year, five years, thirty years, a lifetime). The number of sexual partners that men and women reported desiring over these timepoints was significantly different, in a way that was consistent with evolutionary meta-theory: men reported desiring more sexual partners than women at each 
timepoint. On average, men reported desiring approximately 18 partners over the lifetime, whereas women reported desiring only 4 or 5 (see Figure 2 below, from Buss \& Schmitt, 1993).

Figure 2. Sex differences in the desire for sexual variety

SHORT-TERM AND LONG-TERM SEXUAL STRATEGIES

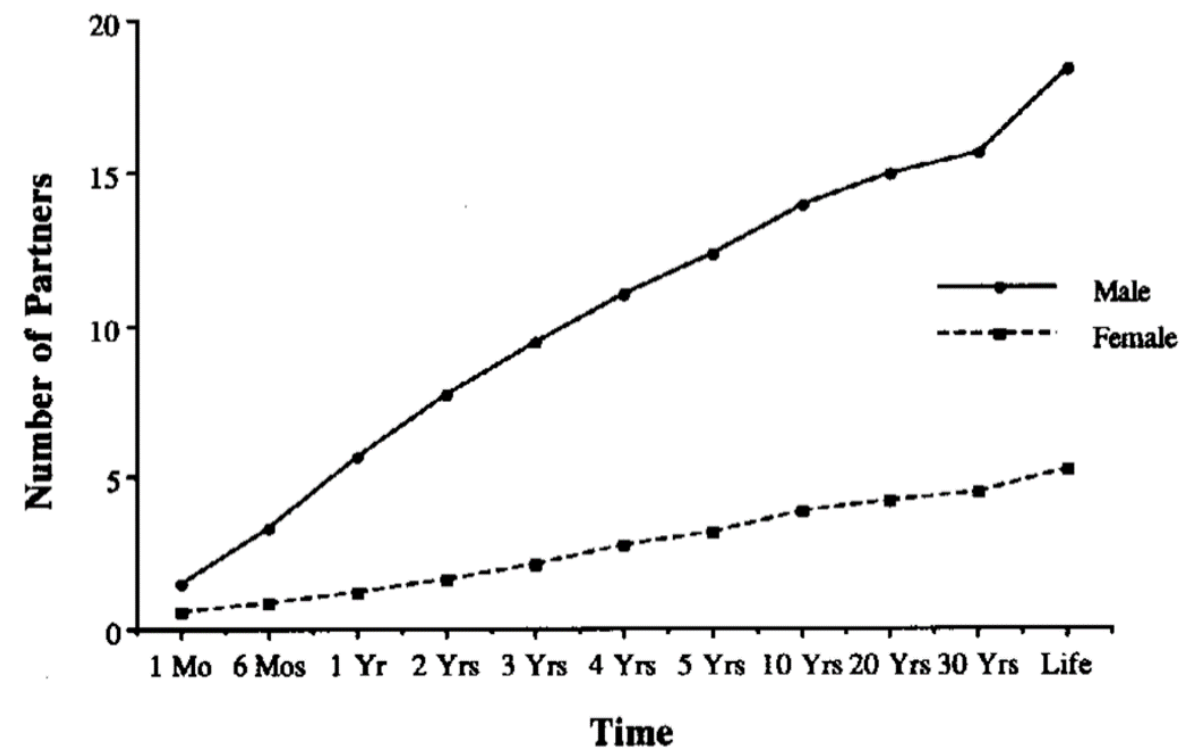

Figure 2. Number of sexual partners desired. (Subjects recorded in blank spaces provided how many sexual partners they would ideally like to have for each specified time interval.)

Note. From "Sexual strategies theory: An evolutionary perspective on human mating" by David M. Buss \& David P. Schmitt, 1993, Psychological Review, 100(2), 204-232.

Buss and Schmitt (1993) described the sex difference in the desire for sexual variety as a core constituent of sexual strategies theory, which itself is heavily influenced by the theory of sexual selection (Darwin, 1859) and parental investment theory (Trivers, 1972). Sexual selection theory posits that (1) individuals (usually men) must often compete with other individuals for access to mates (e.g., intrasexual selection) and (2) individuals (usually women) must try to procure the highest-quality mate possible. Parental investment theory uses sexual selection theory to argue that the sex that invests the most in offspring will be the most discerning when 
selecting partners, as they face higher costs when making injudicious mating decisions and greater benefits when making judicious decisions.

While men and women face similar adaptive problems in some mating-related domains, there are many domains that present unique adaptive problems for each sex. For example, women bear the brunt of the costs when it comes to sexually reproducing, as they are tasked with carrying a fetus to birth, breastfeeding, and the rearing of offspring. Together, sex differences in parental investment (Trivers, 1972) and the intense pressure to choose a partner of high quality necessitate being highly discriminative when navigating the mating market. Buss and Schmitt (1993) argued that as a result of these sex-discrepant adaptive problems, men and women “evolved distinct psychological mechanisms that underlie short and long-term strategies" (p. 204). They also highlighted the importance of temporality in understanding an individual's mating strategy, emphasizing that mate preferences exist on a continuum ranging from shortterm (e.g., brief sexual encounter) to long-term (e.g., marriage) mating and that an individual's mating strategy may change over time. Which mating strategy an individual pursues at a given time will activate a distinct set of behaviors to help the individual achieve the mating strategy of interest.

\section{Measuring sexual desire}

While the Buss and Schmitt (1993) study highlighted the discrepancy in the number of sexual partners desired over various future timepoints, sexual desire as it relates to the urge to engage in sexual intercourse at a given timepoint is characteristically a difficult construct to measure. This difficulty stems from the fact that, unlike sexual arousal, there are no concrete physiological indexes of sexual desire. Because sexual arousal in women consists of vasocongestion and lubrication (e.g., Levin, 1992), it can be assessed with physiological tools 
such as the vaginal photoplethysmograph (e.g., Sintchak \& Geer, 1975) or Schirmer Tear Test strips (e.g., Handy \& Meston, 2020). In contrast, the measurement of sexual desire typically relies on retrospective self-report data, which may be biased in a number of ways (e.g., Meston et al., 1988).

To delineate the cues that make individual women desire solo or dyadic sexual activities, McCall and Meston (2006) asked 50 women to respond to the following question, "What makes you desire sexual activity?" They defined sexual activity as "kissing, petting, oral sex, intercourse, and/or masturbation." From this, they obtained 125 "cues of sexual desire" that they administered to another sample to rate. The results revealed 40 distinct items clustered into four categories of cues associated with desiring sex for women: (1) emotional bonding cues (e.g., feeling a sense of love or commitment); (2) visual/proximity cues (e.g., someone acting confidently); (3) explicit/erotic cues (e.g., talking about sex or having a sexual fantasy); and (4) implicit/romantic cues (e.g., having a romantic dinner with a partner). These cues were linked to individual variation in marital status and sexual functioning. For example, unmarried women or women with higher sexual functioning had higher scores on a composite of the four factors, and were more likely to be triggered by a variety of sexual cues than married women or women with sexual problems.

Understanding individual variation in sexual desire in response to these cues - and in general - is important because of the negative psychological effects that may accompany sexual desire concerns. Concerns with sexual desire are one of the components associated with female sexual dysfunction (FSD). FSD is described in the DSM as an inability to respond to sexual stimuli or to experience sexual pleasure (American Psychiatric Association, 2013). Sexual dysfunction is non-homogenous and can include problems with arousal, desire, orgasm, or sexual 
pain (see Meston \& Stanton, 2017, for prevalence rates of FSD). According to the DSM-5, this inability must be significantly distressing to the individual and must occur for at least six months to meet clinical diagnostic criteria. Of all the sexual concerns, sexual desire concerns are described as the hardest to treat (Goldstein et al., 2016). Difficulty treating sexual desire concerns may stem from the fact that sexual desire is one of the top sexual concerns for women (Basson, 2002; Everaerd et al., 2000; Fisher et al., 1999; Laumann et al., 1999). For example, the prevalence rate of sexual desire concerns among women with sexual difficulties is estimated to be around 64\% (e.g., Hayes et al., 2006). For women in the general population, prevalence rates are closer to $10 \%$ (Goldstein et al., 2016). Sexual desire is also comorbid with other psychological concerns such as depression, anxiety, and fatigue (Goldstein et al., 2016). Together, decrements in sexual desire have been associated with low body-image, low selfconfidence, and more partner-related concerns (Kingsberg, 2014). Understanding the etiology of sexual desire concerns is important for advancing our knowledge of women's sexuality.

Despite the extensive empirical exploration of sexual desire and progress in uncovering its measurement and clinical properties, only one field explains the proper biological function of this phenomenon: evolutionary psychology. An evolutionary psychological perspective of the functions of sexual desire may shed light on how deficits in sexual desire emerge. Uncovering the ontogeny of these deficits may be useful for clinicians to bear in mind when helping patients understand and overcome their sexual desire concerns. More specifically, taking an evolutionary psychological approach to understanding women's sexual desire allows us to ask the questions: why do women experience sexual desire, and how might women vary in their experience of sexual desire?

\section{How can an evolutionary perspective of sexual desire offer insight?}


Before delving in to an evolutionary perspective of female sexual desire, it is important to distinguish between ultimate and proximate explanations. Proximate explanations explain how specific features of an organism develop across the lifespan, and how these features operate in the modern environment. Ultimate explanations refer to why a specific feature of an organism evolved (Mayr, 1961; Scott-Phillips et al., 2011; Tinbergen, 1963). To take a simple example, consider infant crying. A proximate explanation of infant crying — and perhaps parental attachment more broadly — notes that separation from caregivers produces stress for offspring (Scotts-Phillips et al., 2011; Nettle, 2009; Zeifman, 2001). An ultimate explanation of infant crying posits that parent-offspring attachment (including responsiveness to a crying infant) helps facilitate an offspring's survival. It is important to note that ultimate explanations do not imply that a specific trait or set of behaviors is an adaptation (Buss et al., 1998). However, both explanations are useful in examining the evolutionary origins and functions of human behavior, and for understanding how variation in human behavior may emerge. Considering women's sexual desire from both a proximate and ultimate vantage point is necessary for developing efficacious diagnoses and treatments for women with sexual desire concerns.

The ultimate explanation of women's sexual desire is simple: experiencing sexual desire serves to motivate women towards sexual consummation - thereby indirectly increasing a woman's odds of successful reproduction. Conversely, a proximate explanation of women's sexual desire posits that sexual desire results in reaction to sexual arousal, which occurs in response to exposure to sexual stimuli. In sum, sexual desire motivates women towards sexual consummation and is triggered by a suite of physiological, neurological, and hormonal changes that accompany sexual arousal (Toates, 2009). 
An evolutionary perspective of sexual desire also explains how variation in sexual desire may be produced. Darwin's (1859) theory of natural selection contains three basic tenets: (1) variation, (2) inheritance, and (3) selection. Variation of heritable traits occurs in all species. Such variation is passed down from one generation to another. Finally, organisms differ in their ability to successfully reproduce as a result of this variation, and survival and reproduction do not occur randomly. Below I present a hypothetical example to demonstrate how natural selection may operate on women's sexual desire levels.

Consider the following hypothetical scenario:

- Woman A has genes that activate high levels of sexual desire in response to sexual arousal.

- $\quad$ Woman B has genes that activate zero sexual desire in response to sexual arousal. All else equal, Woman A would presumably be more successful in reproducing than Woman B, as experiencing sexual desire — spontaneous or receptive-would motivate her to engage in sex. However, Woman A may also be at increased risk of contracting STIs, having an unpropitious or untimely pregnancy, being left by a partner and thus forced to raise offspring alone, experiencing reputational damage (e.g., slut shaming; being called "damaged goods") by peers in her social group, being at risk for diagnosable psychological disorders (e.g., hypersexuality), or a host of other deleterious effects if her sexual desire is activated to abnormally high levels and she engages in copious amounts of sex. The potential costs associated with excessively high levels of sexual desire in response to sexual arousal for Woman A may outweigh the relational, psychological, or physical benefits associated with sex in this scenario. Conversely, genes that eliminate sexual desire — such as the genes that Woman B in this hypothetical scenario has - in response to sexual arousal may be detrimental to an individual's reproductive success. While 
sexual desire is not a requisite for women to engage in sex, a lack of sexual desire may cause women to disengage or abstain from sex. Abstaining from sex would likely hinder Woman B from achieving reproductive success.

In sum, either unusually high or low levels of sexual desire can be detrimental for women. Because natural selection requires variation in psychological traits, some women will have higher or lower levels of sexual desire than others. However, natural selection would presumably select for a moderate level of sexual desire as both extremes pose potential costs. More specifically, selection should create context-dependent sexual desire in women, favoring contexts that reliably lead to sexual decisions that avoid costs and provide benefits. If sexual desire is context-dependent, we would expect to find variation in sexual desire in response to recurring adaptive problems such as procuring a mate, parenting, and mate retention. However, there may also be stable individual differences in women's sexual desire that are not attributable to context.

Previous research provides support for variation in women's rate of reported sexual desire (Goldstein, 2016; Meston \& Stanton, 2017), suggesting that sexual desire may depend on a variety of contextual factors including age (e.g., Vance et al., 2020), having children (Low, 2015), relationship quality, satisfaction, or duration (e.g., Moor et al., 2021), and novelty (Toates, 2014). Below, I describe each of these contextual factors' association with sexual desire, relate these associations to evolutionary meta-theory, and highlight avenues for future research.

\section{Age and sexual desire}

Age is tied to individual variation in sexual desire in men and women (Beutel et al., 2008; DeLamater \& Sill, 2005; Hällström et al., 1990; Mulligan \& Moss, 1991; Thomas, 1991; Vance et al., 2020). There is an inverse relationship between the two such that as individuals get older, 
sexual desire declines. A study conducted in 2004 illustrated this inverse relationship in a large, diverse sample. This study asked 27,500 men and women ranging in age from 40 to 80 years from 29 countries to respond to a battery of questionnaires about various sexual concerns (Nicolosi et al., 2004). Whereas $9 \%$ of men reported concerns with sexual desire, a lack of sexual interest was the most commonly reported sexual concern in women (21\% across the 29 countries), and this concern appeared to increase as women got older (see Figure 3 below, from Nicolosi et al., 2004). Notably, sexual desire concerns were strongest among women in Southeast Asia and the Middle East.

Figure 3. Sexual desire concerns among women in the global study of sexual attitudes and behaviors

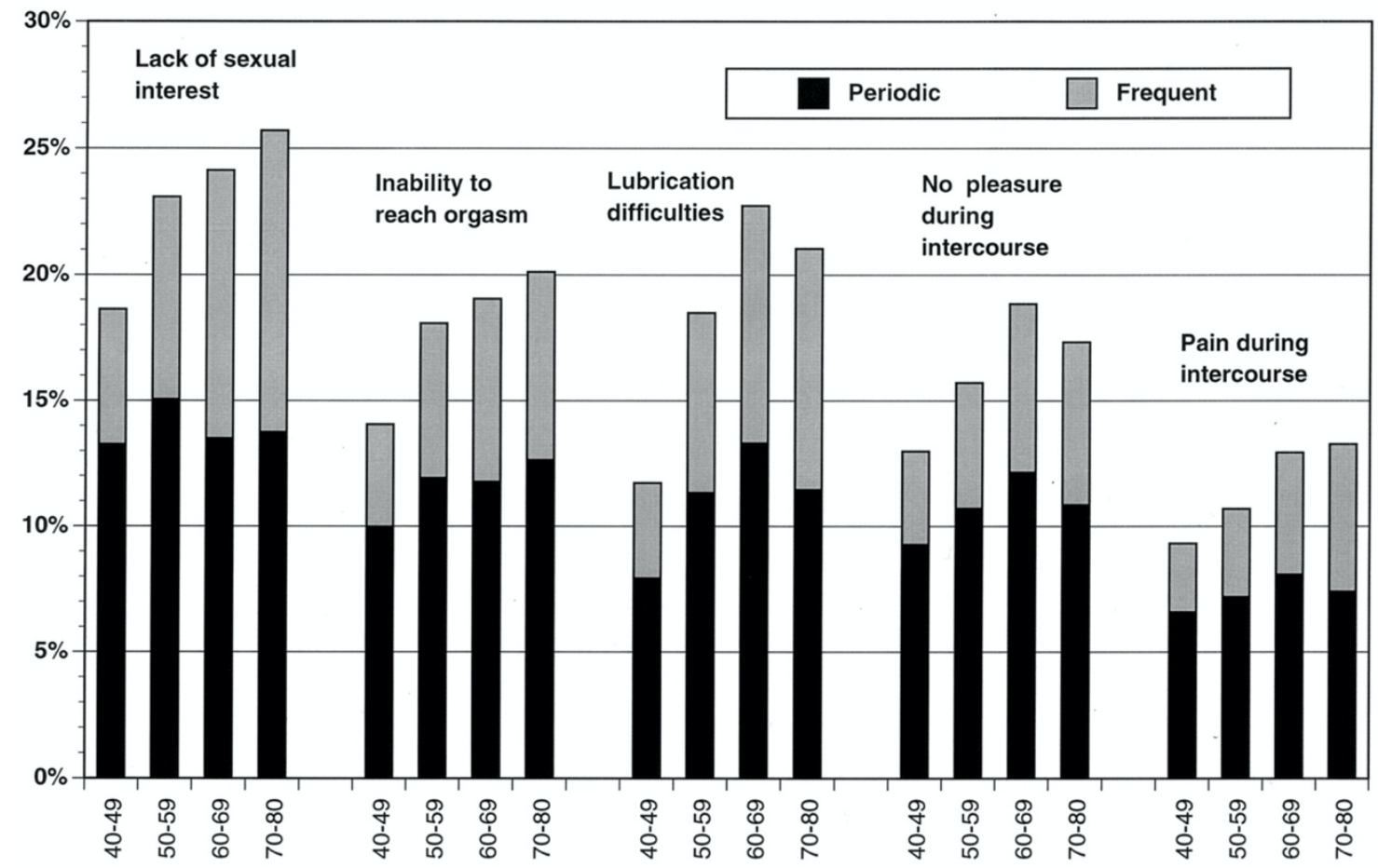

Age group (years)

Note. From "Nicolosi, A., Laumann, E. O., Glasser, D. B., Moreira Jr, E. D., Paik, A., \& Gingell, C. (2004). Sexual behavior and sexual dysfunctions after age 40: The global study of sexual attitudes and behaviors. Urology, 64(5), 991-997." 
This inverse association has been replicated and appears to be large and robust (Beutel et al., 2008; DeLamater \& Sill, 2005; Vance et al., 2020). However, it is important to note that age is accompanied by a host of other physiological and psychological changes that may be driving reported decrements in sexual desire. For example, Howard and colleagues (2006) attributed agerelated declines in sexual desire to external environmental factors such as living alone, illness (see also Laumann et al., 1999), or the loss of a spouse (e.g., death or divorce). Further, as individuals age, they are at increased risk for depression (Stordal et al., 2003), are more likely to have had children, and are more likely to take medications that impair sexual desire (Krapf et al., 2016; Qato et al., 2008). Failing to account for these factors - and others — when examining the association between sexual desire and age could be detrimental, as any reported effects may be artificially conflated.

Evidence of extraneous variables impacting the association between age and sexual desire was documented by DeLameter and Sill (2005). In this study, the authors found that although there was an inverse association between sexual desire and age, individuals were still reporting non-trivial rates of sexual desire. Being in a relationship was central to women's reported rates of sexual desire, whereas education was an important predictor of men's reported rates of sexual desire. Without accounting for education or relationship status, the researchers may have incorrectly concluded that age was the sole predictor of decrements in sexual desire.

In sum, although there is an inverse association between age and sexual desire, there are many potential external factors driving this association. Declines in sexual desire as individuals get older may be a secondary effect to other age-related decrements such as alterations in hormone function, loss of a partner, or parental care.

\section{Parental care and sexual desire}


As women get older, their priorities may shift from mating to parenting (Low, 2015). Parental care encapsulates the costs and benefits involved in the rearing of offspring such as time, energy, and resources (Trivers, 1972; 1974). Parental care is critical for the development of offspring, especially in humans who take notably longer to mature (Kuzawa et al., 2014). At a minimum, women must invest an average of nine months in their offspring. The minimum amount of time women must invest is often longer, however, as nine months does not consider the time and energy invested in lactation, which can last up to four years in some women (e.g., !Kung women; Shostak, 1981). Investing time, energy, and resources into offspring increases the rate of offspring survival, which impacts the parent's reproductive success (Trivers, 1974). Failing to down-regulate sexual desire levels to focus effort on parenting may pose serious evolutionary costs for women (e.g., infant mortality). We should therefore expect women with children - especially younger children who are not yet efficient at taking care of themselves - to report lower levels of sexual desire.

When examining the impact of having children on women's sexual desire, the evidence is consistent with evolutionary meta-theory: women who have children report lower levels of sexual desire than women without children (e.g., Dewitte \& Mayer, 2018). Although there are no studies investigating if this effect is strongest when children are young, frequency of intercourse is lower with young children. When children reach the age of about six years, however, the negative association between child age and frequency of intercourse between parents diminishes (Schröder \& Schmiedeberg, 2015). That is, there appears to be a linear relationship between child age and sexual frequency, with frequency of sex increasing incrementally as children get older and become more autonomous. Future research might test this apparent linear relationship 
as it relates to sexual desire while controlling for potential confounds such as age, medication use, illness, and relationship factors.

\section{Relationship factors and sexual desire}

One of the reasons women are motivated to engage in sex is the desire for emotional bonding, which may signal commitment or love to a partner (Buss, 2003; Carroll et al., 1985; Meston \& Buss, 2007; Townsend, 1998). However, this motivation may "wax and wane" as relationship duration increases (McCall \& Meston, 2007). Relationship length is one of the strongest predictors of declines in sexual desire (Durr, 2009a; Laan \& Both, 2008; Moor et al., 2021; Murray \& Millhausen, 2012). Specifically, women's sexual thoughts or fantasies occur at high levels in the beginning of a romantic relationship, but decline rapidly over the course of a relationship (Basson, 2002; Durr, 2009b; Ferreira et al., 2016; Klusmann, 2002; Kontula \& Haavio-Mannila, 2009; Levine, 2002; Ling \& Kasket, 2016). Relationship length predicting declines in sexual desire appears to be sex-differentiated, with women experiencing declines more often than men, who typically desire, think, or fantasize about sex often regardless of relationship status or length (Fisher et al., 2012; see Moor et al., 2021, for a review). Similar to the association between age and sexual desire, there may be extraneous variables influencing the association between relationship length and sexual desire that need to be controlled for. Potential external factors include a shift in a female partner's priorities, the dyad's level of sexual communication, and changes in the male partner's mate value.

\section{Changes in a female partner's priorities}

As discussed earlier, women have less to gain from having higher quantities of sex than men (Buss \& Schmitt, 1993). Instead, it is important for women to secure a high-quality mate, especially for long-term partnerships. Although speculative, it is possible that the high levels of 
sexual desire women experience at the beginning of romantic partnerships represents a "bait and switch" tactic. Women's higher levels of sexual desire at the beginning of relationships may represent efforts to bait — or secure — a high-quality mate. By being more motivated to engage in dyadic sex with new partners, a woman may be able to fulfill her partner's sexual needs or sexual fantasies. In turn, her partner may be less likely to seek out other romantic partnerships. After successfully securing a mate, women's sexual interest may decline as they switch their priorities to parental care, as discussed in the previous section.

It is also possible that women use sex as a mate retention tactic as relationships progress. A mate retention tactic is a behavior that increases the likelihood that a romantic partner will remain committed to the relationship (Buss et al., 2008). If this is true, we might expect that when women engage in sex with their partner-irrespective of their own sexual desire - they reap incremental gains in commitment from their partner. Further, when women face a mate retention problem, they may experience increases in sexual desire; engaging in sex in response to potential threats may facilitate partner retention. Though there is no research directly examining this hypothesis, there is preliminary evidence that provides insight into this as a possibility. For example, relationship duration is associated with higher levels of sexual satisfaction such that the longer a couple is together, the more sexually satisfied they are (Heiman et al., 2011). This effect exists despite reported declines in sexual desire over the course of a relationship, suggesting that when couples do engage in sex, they are more satisfied. In turn, higher levels of sexual satisfaction are related to greater commitment (e.g., Sprecher, 2002). Future research should keep this possibility in mind, and study the impact of having sex for partner retention purposes (e.g., duty sex; Meston \& Buss, 2007) on reported commitment from male partners.

\section{Communication ability and sexual desire}


Sexual communication issues between relationship partners are one of the leading factors associated with deficits in women's sexual desire as relationships progress (e.g., Træen et al., 2007). Because there is variability in the likes and dislikes of certain sexual behaviors, activities, or fantasies (Lehmiller, 2018), it is important to provide feedback to sexual partners. Failing to do so can result in a lack of trust between partners, anger at a partner, or relationship dissolution (e.g., Montesi et al., 2012). Better communication between partners is associated with many positive outcomes including higher overall satisfaction and sexual satisfaction (e.g., Banmen \& Vogel, 1985; Byers \& Demmons, 1999; Sprecher, 2006).

\section{Changes in a partner's status}

The social status of a partner may also predict women's sexual desire in the context of a romantic relationship. Women and men are motivated to secure the highest-quality mate that they can attract and retain. This is especially true when trying to secure a long-term mate. Typically, high-quality long-term mates in women's eyes consist of someone who has high social status and is dependable, intelligent, and educated (e.g., Shackelford et al., 2005). By choosing a high-status mate, women are indirectly protecting themselves and their offspring from exploitation and increasing their access to desirable resources (e.g., money, food, shelter). Declines in a male partner's status may increase women's vulnerability on multiple fronts. Although speculative, perhaps women's sexual desire levels are sensitive to changes in a partner's status. By signaling to one's partner that sexual desire has waned as a result of a status change, women may be signaling to their partners that their relationship is at risk.

Although there is no research investigating this association directly, preliminary evidence of the impact of status on women's sexual desire was uncovered in a cross-sectional analysis of 7,247 Swiss individuals (Domenighetti et al., 2009). The researchers examined the impact of job 
insecurity on reported sexual desire levels in participants aged 20-64 years. This study was a part of the Swiss Health Survey (SHS), a five-year cross-sectional study. Job insecurity in this study referred to the fear associated with losing a current job, and sexual desire referred to decreases in sexual desire during the previous two weeks. Results revealed that for women between the ages of 20-49 years, depression, their own job insecurity, and marriage status were related to declines in sexual desire. Among older women aged 50-64 years, depression, their own job insecurity, profession, and body mass index were associated with declines in sexual desire. When comparing women with and without job insecurity, results revealed that women with job insecurity were more likely to have sexual desire concerns. Although this study did not examine the impact of partner status on women's sexual desire, it provides preliminary evidence of the link between status, feelings of security, and resource acquisition ability on women's sexual desire. Future research should investigate the impact of male partner status changes on women's sexual desire. It would be interesting to collect this data longitudinally to see if changes in partner status predict changes in women's sexual desire when controlling for potential confounds such as age and relationship length.

\section{Changes in a partner's hygiene}

Individuals consider having sex with someone who has poor hygiene (e.g., bad breath or body odor) sexually disgusting (Crosby et al., 2020). Sexual disgust is an emotion hypothesized to aid in mate selection, guiding women away from costly mates or sexual situations (Tybur et al., 2009). Researchers hypothesize that this emotion may exist on a continuum of sexual motivation, with sexual desire — or lust_-being the opposite of sexual disgust (Lieberman \& Patrick, 2018). Having sex with someone with poor hygiene may expose women to pathogens, which is costly from an evolutionary perspective. Changes in a partner's hygiene over time may 
activate sexual disgust and decrease women's sexual desire. While declines in a partner's hygiene have not been directly examined as they relate to levels of sexual desire in dyads, a loss of attraction to a partner is a common reason women list when discussing sexual desire concerns. This finding is particularly relevant because attraction is inversely related to sexual disgust. That is, the less attractive individuals are, the more sexual disgust they illicit (Crosby et al., under review). If disgust and sexual desire truly exist on a continuum (Lieberman \& Patrick, 2018), then changes in cues associated with disgust activation in a partner (e.g., hygiene) will impact sexual desire in women. Perhaps it would be of interest for researchers to experimentally manipulate the reported hygiene of a potential mate and subsequently observe how these manipulations impact sexual desire in short and long-term contexts.

Habituation, novelty, and sexual desire

Another potential factor that may explain the inverse association between sexual desire and relationship length is habituation (Call et al., 1995). Habituation refers to a decreased emotional or physical response that accompanies prolonged exposure to a stimulus. In the context of romantic relationships, long-term exposure to a partner may affect women's sexual desire levels. The more a woman sees her partner, the less motivated she may be to engage in sexual activity with that partner over time (Sims \& Meana, 2010). For example, women and men experience a drop in sexual arousal following repeated exposure to the same sexual stimuli (e.g., erotic films; Both et al., 2011; Meuwissen \& Over, 1990). While no research has examined if prolonged exposure to sexual stimuli or specific partners is associated with reductions in desire per se, women often cite boredom as a factor in the decline of their partnered sexual activities (e.g., Tunariu \& Reavey, 2003). 
How can we resolve the impact of habituation on women's sexual arousal and, potentially, women's sexual desire? One answer may be to incorporate novelty. Novelty—or exposure to a new romantic or sexual partner-can jumpstart a stagnant sex drive (Toates, 2014). This is known as the Coolidge Effect. The Coolidge Effect has been documented in many species (see Morton \& Gorzalka, 2015 for a review). In humans, this effect has primarily been documented in men. However, the impact of novelty on increasing sex drive has been documented in women, as well. For example, Fisher (2004) argued that because novelty has been associated with surges in dopamine, incorporating novel sexual behaviors or activities may help re-ignite sexual desire in couples. Future research might investigate novelty (e.g., partner novelty, or novel sexual activities) as a treatment for women's sexual desire concerns while being mindful of their desire for sexual variety, age, and relationship length.

\section{When sexual desire is too much}

Toates (2009) argued that sexual desire can be as addictive as cocaine. While the experience of sexual desire is hypothesized to motivate women to have sex, extremely high levels of sexual desire may be detrimental. For example, women suffer biological, reputational (Gallup et al., 2009), and psychological costs when engaging in copious amounts of sex (e.g., AlShawaf et al., 2018). Women are more susceptible to STIs than men, and they incur greater costs when contracting them, including sterility (e.g., Al-Shawaf et al., 2018). Historically, several clinical diagnoses have been associated with excess levels of sexual desire. Examples include hypersexual $^{3}$ disorder, excessive sexual desire (International Classification of Diseases; ICD-10), and compulsive sexual behavior (CSB; see Derbyshire \& Grant, 2015). All three disorders refer

\footnotetext{
${ }^{3}$ Hypersexual disorder was recently rejected by the American Psychiatric Association (APA) and is not included in the DSM-5. However, Krueger (2016) explains that: "Diagnosis of hypersexual or compulsive sexual behavior can be made using ICD-10 and DSM-5 despite rejection of this diagnosis by the American Psychiatric Association" (p. $2,110)$.
} 
to an excess preoccupation with sexual desire, fantasies, or urges. These preoccupations cause significant distress for individuals, and can be associated with social or psychological deficits. Further, CSB can be split into paraphilic or non-paraphilic categories. Paraphilic behaviors include behaviors that are condemned by society or behaviors that include non-human objects. Examples of paraphilic behaviors include pedophilia, exhibitionism, and voyeurism. Nonparaphilic behaviors include pornography addiction, sexual addiction, and compulsive masturbation. Prevalence rates of CSB in the United States are estimated to range from 3-6\% (see Kowalewska et al., 2020, for a review of the prevalence rates of CSB for men and women separately). Women with CSB are described to sometimes participate in compulsive sexual behaviors to reduce anxiety (Roller, 2007). What then, can explain the non-trivial prevalence rates of excessive levels of sexual desire?

\section{Evolutionary mismatch and sexual desire}

One reason for non-zero rates of CSB may be evolutionary mismatch. An evolutionary mismatch refers to qualities of an organism that were selected for in a given environment that are activated at inappropriate rates or times in the modern environment. Sexual desire may become activated in the current environment at a higher frequency than it was selected for (Toates, 2014). Because we evolved in small hunter-gatherer groups with limited exposure to other tribes, sexual desire may have played a critical role in partner selection. By desiring a partner of high quality, a woman may have increased her reproductive success by non-trivial amounts. In this context, sexual desire would have been useful. Natural selection would presumably have retained this motivational process. Fast-forward to modern times, however, and one can see how sexual desire may be activated to potentially pathological levels. Further, with the advent of makeup, hair coloring, and cosmetic surgery, individuals may be creating a supernormal stimulus of 
themselves (Toates, 2014). A supernormal stimulus refers to an exaggerated stimulus that elicits an exaggerated response. This term comes from the learning and memory literature and is typically studied as it relates to rats. However, it may useful when thinking about potential excess activations of sexual desire.

\section{Food for thought: an evolutionary view of disorder}

The DSM-5 diagnosis of a disorder stands in contrast to an evolutionary conceptualization of a mental disorder. According to Wakefield (2007), for a mental condition to be considered a disorder, an evolved mechanism must (1) fail to function as it was designed to function by natural selection and (2) be viewed negatively by society or the individual. Because sexual desire is not necessary for sexual reproduction for women, experiencing low levels of sexual desire may not mean that the mechanism itself is malfunctioning. It seems concerning, then, that such a large percentage of women would be considered sexually disordered under the DSM's definition. This calls into question the DSM's definition of sexual disorders or dysfunction. By labeling women as disordered, clinicians may be inadvertently increasing women's negative emotional reactions about sex, including anxiety, worry, or disgust. These emotions might, in turn, increase women's vulnerability for sexual dysfunction (Zietsch et al., 2011). Clinicians and researchers should be cautious of this potential language feedback loop when treating women with sexual concerns (Barlow, 1986; McCall \& Meston, 2007).

\section{Conclusion}

Sexual desire is a complex motivational force that has important implications for women's sexuality. An evolutionary psychological prospective of sexual desire provides insight into why context-dependent variation in sexual desire may have been selected for, and how high or low levels of sexual desire may lead to biological, psychological, or social deficits. 
Understanding how individual differences in sexual desire can be explained by evolutionary meta-theory may be useful for clinicians when developing treatments for women with sexual desire concerns.

\section{Conflict of Interest}

The authors declare that there are no conflicts of interest to report. 


\section{References}

Al-Shawaf, L., Lewis, D. M., \& Buss, D. M. (2018). Sex differences in disgust: Why are women more easily disgusted than men?. Emotion Review, 10(2), 149-160.

American Psychiatric Association. (2013). Diagnostic and statistical manual of mental disorders (5th ed.). Washington, DC: Author.

American Sexual Health Association. (2016). Prevention tips. Retrieved from http://www.ashasexualhealth.org/stdsstis/prevention-tips/

Baggaley, R. F., White, R. G., \& Boily, M. (2010). HIV transmission risk through anal intercourse: Systematic review, meta-analysis and implications for HIV prevention. International Journal of Epidemiology, 39(4), 1048-1063. doi:10.1093/ije/dyq057

Banmen, J., \& Vogel, N. A. (1985). The relationship between marital quality and interpersonal sexual self-disclosure. Family Therapy, 12, 45-58.

Barlow, D. H. (1986). Causes of sexual dysfunction: The role of anxiety and cognitive interference. Journal of Consulting and Clinical Psychology, 54(2), 140.

Basson, R. (2002). Rethinking low sexual desire in women. BJOG: An International Journal of Obstetrics \& Gynaecology, 109(4), 357-363.

Basson, R. (2000). The female sexual response revisited. Journal SOGC, 22(5), 378-382.

Bendixen, M. (2014). Evidence of systematic bias in sexual over-and underperception of naturally occurring events: A direct replication of in a more gender-equal culture. Evolutionary Psychology, 12(5), 147470491401200510.

Bersamin, M. M., Zamboanga, B. L., Schwartz, S. J., Donnellan, M. B., Hudson, M., Weisskirch, R. S., ... \& Caraway, S. J. (2014). Risky business: Is there an association between casual sex and mental health among emerging adults?. Journal of Sex Research, 51(1), 43-51. 
Beutel, M. E., Stöbel-Richter, Y., \& Brähler, E. (2008). Sexual desire and sexual activity of men and women across their lifespans: Results from a representative German community survey. BJU international, 101(1), 76-82.

Boily, M., Baggaley, R. F., Wang, L., Masse, B., White, R. G., Hayes, R. J., \& Alary, M. (2009). Heterosexual risk of HIV-1 infection per sexual act: Systematic review and meta-analysis of observational studies. The Lancet Infectious Diseases, 9(2), 118-129. doi:10.1016/s1473-3099(09)70021-0

Both, S., Laan, E., \& Everaerd, W. (2011). Focusing "hot" or focusing “cool": Attentional mechanisms in sexual arousal in men and women. The Journal of Sexual Medicine, 8(1), $167-179$.

Brotto, L. A. (2010). The DSM diagnostic criteria for hypoactive sexual desire disorder in women. Archives of Sexual Behavior, 39(2), 221-239.

Buss, D. M., \& Schmitt, D. P. (2019). Mate preferences and their behavioral manifestations. Annual Review of Psychology, 70, 77-110.

Buss, D. M., Shackelford, T. K., \& McKibbin, W. F. (2008). The mate retention inventory-short form (MRI-SF). Personality and Individual Differences, 44(1), 322-334.

Buss, D. M. (2003). The evolution of desire: Strategies of human mating (rev. ed.). New York: Basic Books.

Buss, D. M., Haselton, M. G., Shackelford, T. K., Bleske, A. L., \& Wakefield, J. C. (1998). Adaptations, exaptations, and spandrels. American Psychologist, 53(5), 533.

Buss, D. M., \& Schmitt, D. P. (1993). Sexual strategies theory: An evolutionary perspective on human mating. Psychological Review, 100(2), 204. 
Byers, E. S., \& Demmons, S. (1999). Sexual satisfaction and sexual self-disclosure within dating relationships. Journal of Sex Research, 36, 180-189. doi:10.1080/00224499909551983.

Call, V., Sprecher, S., \& Schwartz, P. (1995). The incidence and frequency of marital sex in a national sample. Journal of Marriage and the Family, 639-652.

Carroll, J. L., Volk, K. D., \& Hyde, J. S. (1985). Differences between males and females in motives for engaging in sexual intercourse. Archives of Sexual Behavior, 14(2), 131-139.

Centers for Disease Control and Prevention. (2008). Incidence, prevalence, and cost of sexually transmitted infections in the United States. Retrieved from http://www.cdc.gov/std/stats/sti-estimates-fact-sheetfeb-2013.pdf

Crosby, C. L., Buss, D. M., Cormack, L. K., \& Meston, C. M. (2021). Sex, sexual arousal, and sexual decision-making: An evolutionary perspective. Personality and Individual Differences, 177, 1-5.

Crosby, C. L., Buss, D. M., \& Meston, C. M. (2019). Sexual disgust: Evolutionary perspectives and relationship to female sexual function. Current Sexual Health Reports, 11(4), 300306.

Crosby, C. L., Durkee, P. K., Meston, C. M., \& Buss, D. M. (2020). Six dimensions of sexual disgust. Personality and Individual Differences, 156, 109714.

Crosby, C. L., Durkee, P. K., Sedlacek, A. B. G., \& Buss, D. M. (Stage 2 Registered Report: under review). Mate availability and sexual disgust. Adaptive Human Behavior and Physiology. https://osf.io/g9us7/

Daly, M. (2001). Risk-taking, intrasexual competition, and homicide. Evolutionary Psychology and Motivation, 47. 
Darwin, C. (1958). On the origin of species by means of natural selection. (New York: New American Library. (Original work published 1859)

DeLamater, J. D., \& Sill, M. (2005). Sexual desire in later life. Journal of Sex Research, 42(2), 138-149.

Derbyshire, K. L., \& Grant, J. E. (2015). Compulsive sexual behavior: A review of the literature. Journal of Behavioral Addictions, 4(2), 37-43.

Dewitte, M., \& Mayer, A. (2018). Exploring the link between daily relationship quality, sexual desire, and sexual activity in couples. Archives of Sexual Behavior, 47(6), 1675-1686.

Diagnostic and Statistical Manual of Mental Disorders (DSM-III-R). 3rd rev. Washington, DC: American Psychiatric Association; 1987.

Diagnostic and Statistical Manual of Mental Disorders (DSM-III). 3rd ed. Washington, DC: American Psychiatric Association; 1980.

Domenighetti G., Tomada A., Marazzi A., Abazi O., \& Quaglia, J. (2009). Impact of job insecurity on sexual desire: An exploratory analysis. Swiss Medical Weekly, 139(3334), 486-492.

Durr, E. (2009a). Women's experience of lack of sexual desire in relationships and implications for interventions. Social Work, 45(3), 256-274.

Durr, E. (2009b). Lack of 'responsive' sexual desire in women: Implications for clinical practice. Sexual and Relationship Therapy, 24(3-4), 292-306. https://doi.org/10.1080/14681990903271228

Ellis, B. J., \& Symons, D. (1990). Sex differences in sexual fantasy: An evolutionary psychological approach. Journal of Sex Research, 27(4), 527-555. 
Eshbaugh, E. M., \& Gute, G. (2008). Hookups and sexual regret among college women. The Journal of Social Psychology, 148(1), 77-90

Everaerd, W. (2000). Laan A. N. D., Both S., Van der Velde J. Female sexuality. In: Szuchman L, Muscarella F, editors. Psychological perspectives on human sexuality. New York: John Willey \& Sons, 101-46.

Ferreira, L. C., Narciso, I., Ferreira Novo, R., \& Pereira, C. R. (2016). Partners' similarity in differentiation of self is associated with higher sexual desire: A quantitative dyadic study. Journal of Sex \& Marital Therapy, 42(7), 635-647. https://doi.org/10.1080/0092623X.2015.1113584

Fisher, T. D., Moore, Z. T., \& Pittenger, M. J. (2012). Sex on the brain?: An examination of frequency of sexual cognitions as a function of gender, erotophilia, and social desirability. Journal of Sex Research, 49(1), 69-77.

Fisher, H. (2004) Why We Love: The Nature and Chemistry of Romantic Love. Henry Holt, NY.

Fisher, W. A., Boroditsky, R., \& Bridges, M. L. (1999). The 1998 Canadian Contraception Study. Canadian Journal of Human Sexuality, 8(3), 161-216.

Freud, S. (2017). Three essays on the theory of sexuality: The 1905 edition. Verso Books. Gallup, A. C., O’Brien, D. T., White, D. D., \& Wilson, D. S. (2009). Peer victimization in adolescence has different effects on the sexual behavior of male and female college students. Personality and Individual Differences, 46(5-6), 611-615.

Goldstein, I., Kim, N. N., Clayton, A. H., DeRogatis, L. R., Giraldi, A., Parish, S. J., ... \& Worsley, R. (2016). Hypoactive sexual desire disorder: International Society for the Study of Women's Sexual Health (ISSWSH) expert consensus panel review. In Mayo clinic proceedings (Vol. 92, No. 1, pp. 114-128). Elsevier. 
Hällström, T., \& Samuelsson, S. (1990). Changes in women's sexual desire in middle life: The longitudinal study of women in Gothenburg. Archives of Sexual Behavior, 19(3), 259268.

Handy, A. B., \& Meston, C. M. (2020). An objective measure of vaginal lubrication in women with and without sexual arousal concerns. Journal of Sex \& Marital Therapy, 47(1), 3242.

Haselton, M. G., \& Buss, D. M. (2000). Error management theory: A new perspective on biases in cross-sex mind reading. Journal of Personality and Social Psychology, 78(1), 81.

Hayes, R. D., Bennett, C. M., Fairley, C. K., \& Dennerstein, L. (2006). Epidemiology: What can prevalence studies tell us about female sexual difficulty and dysfunction?. The Journal of Sexual Medicine, 3(4), 589-595.

Heiman, J. R., Long, J. S., Smith, S. N., Fisher, W., Sand, M. S., \& Rosen, R. C. (2011). Sexual satisfaction and relationship happiness in midlife and older couples in five countries. Archives of Sexual Behavior, 40, 741-753. doi:10.1007/s10508-010-9703-3

Howard, J. R., O'Neill, S., \& Travers, C. (2006). Factors affecting sexuality in older Australian women: sexual interest, sexual arousal, relationships and sexual distress in older Australian women. Climacteric, 9(5), 355-367.

Kaplan, H. S. (1977). Hypoactive sexual desire. Journal of Sex \& Marital Therapy, 3(1), 3-9.

Kennair, L. E. O., Bendixen, M., \& Buss, D. M. (2016). Sexual regret: Tests of competing explanations of sex differences. Evolutionary Psychology, 14(4), 1474704916682903.

Kingsberg, S. A. (2014). Attitudinal survey of women living with low sexual desire. Journal of Women's Health, 23(10), 817-823. 
Klusmann, D. (2002). Sexual motivation and duration of partnership. Archives of Sexual Behavior, 31(3), 257-287. https://doi.org/10.1023/ A:1015205020769

Kontula, O., \& Haavio-Mannila, E. (2009). The impact of aging on human sexual activity and sexual desire. Journal of Sex Research, 46 (1), 46-56. https://doi.org/10.1080/00224490802624414

Kowalewska, E., Gola, M., Kraus, S. W., \& Lew-Starowicz, M. (2020). Spotlight on compulsive sexual behavior disorder: A Systematic Review of Research on Women. Neuropsychiatric Disease and Treatment, 16, 2025.

Krapf, J. M., Buster, J. E., \& Goldstein, A. T. (2016). Management of hypoactive sexual desire disorder (HSDD). In Management of sexual dysfunction in men and women (pp. 233249). Springer, New York, NY.

Krueger, R. B. (2016). Diagnosis of hypersexual or compulsive sexual behavior can be made using ICD-10 and DSM-5 despite rejection of this diagnosis by the American Psychiatric Association.

Kuzawa, C. W., Chugani, H. T., Grossman, L. I., Lipovich, L., Muzik, O., Hof, P. R., ... \& Lange, N. (2014). Metabolic costs and evolutionary implications of human brain development. Proceedings of the National Academy of Sciences, 111(36), 13010-13015

Laan, E., \& Both, S. (2008). What makes women experience desire? Feminism \& Psychology, 18(4), 505-514. https://doi.org/10.1177/ 0959353508095533

Laumann, E. O., Paik, A., \& Rosen, R. C. (1999). Sexual dysfunction in the United States: prevalence and predictors. Jama, 281(6), 537-544.

Lehmiller, J. J. (2018). Tell me what you want: The science of sexual desire and how it can help you improve your sex life. Da Capo Press: Boston, MA. 
Leiblum, S. R. (2000). Redefining female sexual response. Contemporary Ob/Gyn, 45(11), 120120.

Levine, S. B. (2003). The nature of sexual desire: A clinician's perspective. Archives of Sexual Behavior, 32(3), 279-285.

Levine, S. B. (2002). Reexploring the concept of sexual desire. Journal of Sex \& Marital Therapy, 28(1), 39-51. https://doi.org/10.1080/ 009262302317251007

Levin, R. (1992). The mechanisms of human female sexual arousal. Annual Review of Sex Research, 3(1), 1-48.

Lieberman, D., \& Patrick, C. (2018). Objection: Disgust, morality, and the law. Oxford University Press.

Ling, J., \& Kasket, E. (2016). Let's talk about sex: A critical narrative analysis of heterosexual couples' accounts of low sexual desire. Sexual and Relationship Therapy, 31(3), 325342.

Low, B. S. (2015). Why Sex Matters: A Darwinian Look at Human Behavior-Revised Edition. Princeton University Press.

Masters, W. H., \& Johnson, V. E. (1966). Human sexual response.

Mayr, E. (1961). Cause and effect in biology. Science, 134(3489), 1501-1506.

McCall, K. M., \& Meston, C. M. (2007). The effects of false positive and false negative physiological feedback on sexual arousal: A comparison of women with or without sexual arousal disorder. Archives of Sexual Behavior, 36(4), 518-530.

McCall, K., \& Meston, C. (2006). Cues resulting in desire for sexual activity in women. The Journal of Sexual Medicine, 3(5), 838. 
Meston, C. M., \& Stanton, A. M. (2017). Recent findings on women's motives for engaging in sexual activity. Current Sexual Health Reports, 9(3), 128-135.

Meston, C. M., \& Buss, D. M. (2007). Why humans have sex. Archives of Sexual Behavior, $36(4), 477-507$.

Meston, C. M., Heiman, J. R., Trapnell, P. D., \& Paulhus, D. L. (1998). Socially desirable responding and sexuality self-reports. The Journal of Sex Research, 35(2).

Meuwissen, I., \& Over, R. (1990). Habituation and dishabituation of female sexual arousal. Behaviour Research and Therapy, 28(3), 217-226.

Montesi, J. L., Conner, B. T., Gordon, E. A., Fauber, R. L., Kim, K. H., \& Heimberg, R. G. (2013). On the relationship among social anxiety, intimacy, sexual communication, and sexual satisfaction in young couples. Archives of Sexual Behavior, 42(1), 81-91.

Moor, A., Haimov, Y., \& Shreiber, S. (2021). When desire fades: Women talk about their subjective experience of declining sexual desire in loving long-term relationships. The Journal of Sex Research, 58(2), 160-169.

Morton, H., \& Gorzalka, B. B. (2015). Role of partner novelty in sexual functioning: A review. Journal of Sex \& Marital Therapy, 41(6), 593-609.

Mulligan, T., \& Moss, C. R. (1991). Sexuality and aging in male veterans: a cross-sectional study of interest, ability, and activity. Archives of Sexual Behavior, 20(1), 17-25.

Murray, S. H., \& Milhausen, R. R. (2012). Sexual desire and relationship duration in young men and women. Journal of Sex \& Marital Therapy, 38(1), 28-40.

National Center for HIV/AIDS, Viral Hepatitis, STD, and TB Prevention. (2011). 10 ways STDs impact women differently from men. Atlanta, GA: Centers for Disease Control and Prevention. 
Nettle, D. (2009). Evolution and genetics for psychology. Oxford, England: Oxford University Press.

Nicolosi, A., Laumann, E. O., Glasser, D. B., Moreira Jr, E. D., Paik, A., \& Gingell, C. (2004). Sexual behavior and sexual dysfunctions after age 40: The global study of sexual attitudes and behaviors. Urology, 64(5), 991-997.

Owen, J. J., Rhoades, G. K., Stanley, S. M., \& Fincham, F. D. (2010). “Hooking up” among college students: Demographic and psychosocial correlates. Archives of Sexual Behavior, 39(3), 653-663.

Qato, D. M., Alexander, G. C., Conti, R. M., Johnson, M., Schumm, P., \& Lindau, S. T. (2008). Use of prescription and over-the-counter medications and dietary supplements among older adults in the United States. Jama, 300(24), 2867-2878.

Roller, C. G. (2007). Sexually compulsive/addictive behaviors in women: A women's healthcare issue. Journal of Midwifery \& Women's Health, 52(5), 486-491.

Rowland, D. L., \& and Gutierrez, B. R. (2017). Phases of the sexual response cycle. In A. Wenzel (Ed.), The SAGE Encyclopedia of Abnormal and Clinical Psychology (pp. 17051706). SAGE Publications, Inc.

Schröder, J., \& Schmiedeberg, C. (2015). Effects of relationship duration, cohabitation, and marriage on the frequency of intercourse in couples: Findings from German panel data. Social Science Research, 52, 72-82.

Scott-Phillips, T. C., Dickins, T. E., \& West, S. A. (2011). Evolutionary theory and the ultimateproximate distinction in the human behavioral sciences. Perspectives on Psychological Science, 6(1), 38-47. 
Seth, P., Lang, D. L., DiClemente, R. J., Braxton, N. D., Crosby, R. A., Brown, L. K., .. . Donenberg, G. R. (2012). Gender differences in sexual risk behaviours and sexually transmissible infections among adolescents in mental health treatment. Sexual Health, 9(3), 240-246. doi:10.1071/sh10098

Shackelford, T. K., Schmitt, D. P., \& Buss, D. M. (2005). Universal dimensions of human mate preferences. Personality and Individual Differences, 39(2), 447-458.

Shostak, M. (1981). Nisa: The life and words of a! Kung woman. Cambridge: MA: Harvard University Press.

Sims, K. E., \& Meana, M. (2010). Why did passion wane? A qualitative study of married women's attributions for declines in sexual desire. Journal of Sex \& Marital Therapy, 36(4), 360-380.

Sintchak, G., \& Geer, J. H. (1975). A vaginal plethysmograph system. Psychophysiology, 12(1), 113-115.

Sonnenberg, P., Clifton, S., Beddows, S., Field, N., Soldan, K., Tanton, C., ... \& Phelps, A. (2013). Prevalence, risk factors, and uptake of interventions for sexually transmitted infections in Britain: Findings from the National Surveys of Sexual Attitudes and Lifestyles (Natsal). The Lancet, 382(9907), 1795-1806.

Sprecher, S. (2006). Sexuality in close relationships. In P. Noller \& J. A. Feeney (Eds.), Closer relationships: Functions, forms, and processes (pp. 267-284). Hove: Psychology Press/Taylor \& Francis.

Sprecher, S. (2002). Sexual satisfaction in premarital relationships: Associations with satisfaction, love, commitment, and stability. Journal of Sex Research, 39, 190-196. doi:10.1080/00224490209552141 
Stordal, E., Mykletun, A., \& Dahl, A. A. (2003). The association between age and depression in the general population: a multivariate examination. Acta psychiatrica scandinavica, 107(2), 132-141.

Thomas, L. E. (1991). Correlates of sexual interest among elderly men. Psychological Reports, $68(2), 620-622$.

Thrall, P. H., Antonovics, J., \& Dobson, A. P. (2000). Sexually transmitted diseases in polygynous mating systems: Prevalence and impact on reproductive success. Proceedings of the Royal Society B: Biological Sciences, 267(1452), 1555-1563. doi:10.1098/rspb.2000.1178

Tinbergen, N. (1963). On aims and methods of ethology. Zeitschrift für tierpsychologie, 20(4), 410-433.

Toates, F. (2014). How sexual desire works. Cambridge University Press.

Toates, F. (2009). An integrative theoretical framework for understanding sexual motivation, arousal, and behavior. Journal of Sex Research, 46(2-3), 168-193.

Townsend, J. (1998). What women want-what men want: Why the sexes still see love and commitment so differently. Oxford: Oxford University Press.

Træen, B., Martinussen, M., Öberg, K., \& Kavli, H. (2007). Reduced sexual desire in a random sample of Norwegian couples. Sexual and Relationship Therapy, 22(3), 303-322.

Trivers, R. L. (1974). Parent-offspring conflict. Integrative and Comparative Biology, 14(1), 249-264.

Trivers, R. (1972). Parental investment and sexual selection (Vol. 136, p. 179). Cambridge, MA: Biological Laboratories, Harvard University. 
Tunariu, A. D., \& Reavey, P. (2007). Common patterns of sense making: A discursive reading of quantitative and interpretative data on sexual boredom. British Journal of Social Psychology, 46(4), 815-837.

Tybur, J. M., Lieberman, D., \& Griskevicius, V. (2009). Microbes, mating, and morality: individual differences in three functional domains of disgust. Journal of Personality and Social Psychology, 97(1), 103.

Vance, G., Shackelford, T. K., Weekes-Shackelford, V. A., \& Abed, M. G. (2020). Later life sex differences in sexual psychology and behavior. Personality and Individual Differences, $157,109730$.

Varghese, B., Maher, J. E., Peterman, T. A., Branson, B. M., Steketee, R. W. (2002). Reducing the risk of sexual HIV transmission: Quantifying the per-act risk for HIV on the basis of choice of partner, sex act, and condom use. Sexually Transmitted Diseases, 29:38-43.

Wakefield, J. C. (2007). The concept of mental disorder: diagnostic implications of the harmful dysfunction analysis. World Psychiatry, 6(3), 149.

Zeifman, D. M. (2001). An ethological analysis of human infant crying: answering Tinbergen's four questions. Developmental Psychobiology: The Journal of the International Society for Developmental Psychobiology, 39(4), 265-285.

Zietsch, B. P., Miller, G. F., Bailey, J. M., \& Martin, N. G. (2011). Female orgasm rates are largely independent of other traits: Implications for "female orgasmic disorder" and evolutionary theories of orgasm. The Journal of Sexual Medicine, 8(8), 2305-2316. 